\title{
The effects of restaurant nutrition menu labelling on college students' healthy eating behaviours
}

\author{
Mary G Roseman ${ }^{1, *}$, Hyun-Woo Joung ${ }^{1}$, Eun-Kyong (Cindy) Choi ${ }^{1}$ and Hak-Seon Kim ${ }^{2}$ \\ 'Department of Nutrition and Hospitality Management, The University of Mississippi, University, MS, USA: ${ }^{2}$ School \\ of Hospitality \& Tourism Management, Kyungsung University, 309 Sooyoung-ro, Nam-gu, Busan, Republic of Korea
}

Submitted 14 June 2016: Final revision received 9 August 2016: Accepted 14 September 2016: First published online 10 November 2016

\begin{abstract}
Objective: According to the US Affordable Care Act, restaurant chains are required to provide energy (calorie) and other nutrition information on their menu. The current study examined the impact of menu labelling containing calorie information and recommended daily calorie intake, along with subjective nutrition knowledge, on intention to select lower-calorie foods prior to the implementation of the Affordable Care Act.

Design: Full factorial experimental design with participants exposed to four variants of a sample menu in a 2 (presence $v$. absence of calorie information) $\times 2$ (presence $v$. absence of recommended daily calorie intake).

Setting: Large, public university in the Southwest USA.

Subjects: Primarily undergraduate college students.

Results: Majority of participants were 19-23 years of age (mean 21.8 (sD 3.6) years). Menu information about calorie content and respondents' subjective nutrition knowledge had a significantly positive impact on students' intention to select lower-calorie foods $(\beta=0.24, P<0.001$ and $\beta=0.33, P<0.001$, respectively); however, recommended daily calorie intake information on the menu board did not influence students' intention to select lower-calorie foods $(\beta=0 \cdot 10, P=0 \cdot 105)$. Gender played a significant role on purchase intent for lower-calorie menu items, with females more affected by the calorie information than males $(\beta=0.37$, $P<0 \cdot 001)$.

Conclusions: Findings support the role menu labelling can play in encouraging a healthier lifestyle for college students. College students who are Generation Y desire healthier menu options and accept nutritional labels on restaurant menus as a way to easily and expediently obtain nutrition information.
\end{abstract}

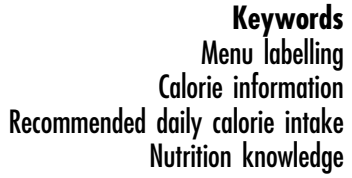

Keywords Calorie information Nutrition knowledge
The consumption of away-from-home meals in the USA has increased dramatically over the years and accounted for $43.1 \%$ of consumers' food budget in 2012, compared with only $25.9 \%$ in $1970^{(1)}$. Increasing interest by consumers in changing their diet ${ }^{(2)}$ and in restaurants being more transparent about menu items ${ }^{(3)}$ has resulted in a desire for restaurants to include nutrition information for patrons. To aid this consumer need, in 2010, the Affordable Care Act was signed into law in the USA, amending section 403(q) of the Federal Food and Drug Act. As amended, section 403(q) requires restaurant chains and similar retail food establishments operating as part of a chain under the same name with twenty or more locations to provide energy (calories, i.e. kilocalories) and other nutrition information for standard menu items, including foods on display, self-service foods, and on menus and menu boards ${ }^{(4)}$. The law takes effect on 5 May $2017^{(5)}$. Its primary purpose is to make nutrition information on restaurant foods available to consumers in a direct, accessible and consistent manner, to enable consumers to make informed and healthful dietary choices ${ }^{(4)}$. Prior to the Affordable Care Act, some cities and states enacted their own laws requiring chain restaurants to post nutrition information on their menu boards and menus ${ }^{(6,7)}$, prompting interest in research on restaurant menu labelling. Initiated in 2010, some major national restaurant chains such as Panera Bread Company and McDonald's began to voluntarily post calories on their menu boards at company-owned stores ${ }^{(8,9)}$.

Generation Y, also known as Millennials, is loosely defined as young adults who were born between 1980 and $2000^{(10)}$, with the first Millennials reaching adulthood around the year $2000^{(11)}$. While the buying power of Generation Y consumers is projected to eclipse that of Baby Boomers ${ }^{(12)}$, there is limited research focusing on their healthy eating and purchase behaviours in restaurants. 
With Generation Y, the number of college students has risen dramatically in the USA; in 2016, nearly 20.5 million students are expected to attend US colleges and universities, constituting an increase of about 5 million since $2000^{(13)}$. The nutrition health of US college students is important; nearly $32 \%$ of college students selfreport a high BMI $\left(>25.0 \mathrm{~kg} / \mathrm{m}^{2}\right)$, classifying them as overweight or obese ${ }^{(14)}$. College students tend to be physically inactive, have little time or ability to cook nutritious meals, are exposed to large portion sizes at eating facilities ${ }^{(15)}$ and like fast foods due to their low cost and convenience ${ }^{(16)}$.

\section{Nutrition information on restaurant menus}

Customers perceive restaurants to be socially responsible when they provide healthful food and nutrition information, with highly health-conscious customers reacting more strongly to healthy foods than their counterparts ${ }^{(17)}$. Data of menu items from the largest restaurant chains for 2012-2013 found that mean calories among menu items did not change, while the amount of calories in newly introduced menu items reduced significantly ${ }^{(18,19)}$.

Much of the research on the effects of restaurant menu labelling encouraging individuals to choose healthier menu items has been mixed. Some research suggests that consumers may not want to be exposed to a menu item's nutrition information or may overstate their use of nutrition labelling ${ }^{(20)}$. Other studies on consumer behaviour before and after the implementation of restaurant menu labelling in the USA find no significant change in the caloric level of menu purchases ${ }^{(21-23)}$. Some studies found a caloric reduction between pre- and post-treatment phases $^{(24)}$ and selections with fewer calories by those viewing nutrition information on menu items when compared with those who did not ${ }^{(25-27)}$. A meta-analysis of six controlled studies in restaurant settings found a nonsignificant reduction in calories ${ }^{(28)}$, with some consumers stating that nutrition labelling is a healthful influence over their purchasing decision ${ }^{(29)}$. Restaurant customers have positive attitudes towards lower-calorie items and these patrons are willing to pay a premium if the information provided indicates healthy nutrition ${ }^{(30)}$.

\section{Generation Y's bealtby eating behaviours}

Generation Y's health concerns are increasing ${ }^{(31)}$; 'healthconscious' and 'adventurous' Generation Y groups seek green restaurants, healthy menus and quality foods ${ }^{(32)}$. Generation Y describe themselves as 'foodies'(33), with a Gallup poll showing that $57 \%$ of Millennials eat at a quickservice restaurant at least once weekly, compared with $47 \%$ of those aged $40-49$ years, $44 \%$ of those aged $50-64$ years and $41 \%$ of those aged 65 years or older ${ }^{(34)}$. While Millennials eat out more often than non-Millennials (3.4 $v$. $2 \cdot 8$ times per week) ${ }^{(35)}$, they are a part of the growing trend towards consumers becoming concerned about their health and the healthiness and quality of the foods they eat ${ }^{(36,37)}$. Therefore, to better understand if restaurant menu labelling affects the calorie intake of college (Generation Y) students, the following two hypotheses were proposed:

H1. Generation $Y$ students have a higher intention to select lower-calorie foods if they are provided calorie information on restaurant menus.

H2. Generation $Y$ students have a higher intention to select lower-calorie foods if they are provided with recommended daily calorie intake information on restaurant menus.

\section{Subjective nutrition knowledge}

Consumer research distinguishes between actual knowledge and subjective knowledge ${ }^{(38)}$ where two conceptually different constructs are defined as: 'objective knowledge, i.e. the accurate information about the product stored in consumer's long-term memory; and subjective knowledge, i.e. people's subjective perceptions of what or how much they know about a product based on their own subjective interpretation of what one knows, ${ }^{\text {(39) }}$. Both forms of knowledge have contributed to the literature; for example, subjective and objective measures of nutrition knowledge are significantly associated with self-reported use of nutrition labels on grocery products ${ }^{(40)}$. While objective knowledge is related to an increase in healthful eating patterns by college students ${ }^{(41)}$, subjective knowledge is also a good predictor - or even a better motivator - than objective knowledge in dietary behaviour and food choices when selecting healthier options from food labels ${ }^{(42)}$. Thus, an additional hypothesis was proposed:

H3. Generation Y students who have higher subjective nutrition knowledge have a higher intention to select lower-calorie foods on restaurant menus.

\section{Hypothesized model}

To better understand the current study, a conceptual framework is depicted in Fig. 1. The hypothesized model includes three independent variables: (i) calorie information, (ii) recommended daily calorie intake information and (iii) subjective nutrition knowledge; a dependent



Fig. 1 Hypothesized conceptual framework 
variable (intention to select lower-calorie foods); and potential confounding variables (gender, age, frequency of dining out, BMI).

\section{Methods}

\section{Research design}

Undergraduate research participants were exposed to four variants of a sample menu in a 2 (presence $v$. absence of calorie information) $\times 2$ (presence $v$. absence of recommended daily calorie intake) full factorial experimental design. Participants saw only one of four versions of stimulus materials in which all possessed consistent menu items, features and descriptions but varied regarding calorie information as follows.

Version 1: No calorie or recommended daily calorie intake information.

Version 2: Only calorie information.

Version 3: Only recommended daily calorie intake information.

Version 4: Both calorie and recommended daily calorie intake information.

Research participants were recruited at a campus cafeteria of a large, public university in the Southwest USA to voluntarily participate in the study. Prior to conducting the research, the study protocol was approved by Texas Tech University's Internal Review Board.

Each version of the sample menu contained six menu items selected from a list of Burger King sandwiches using calorie information from its official website. The sandwiches included BK Veggie Burger: $320 \mathrm{kcal}(1339 \mathrm{~kJ})$; Tendergrill Chicken Sandwich: $360 \mathrm{kcal}$ (1506 kJ); Deluxe Cheeseburger: $420 \mathrm{kcal}(1757 \mathrm{~kJ})$; Whopper Sandwich: $760 \mathrm{kcal}(3180 \mathrm{~kJ})$; Double Whopper Sandwich: $900 \mathrm{kcal}$ $(3766 \mathrm{~kJ})$; and Triple Whopper Sandwich, $1140 \mathrm{kcal}$ $(4770 \mathrm{~kJ})$. Fifty participants were exposed to the stimulus materials for each version of the menu. Participants were randomly selected regarding the menu version they viewed. To randomize the menus, five field researchers were located in the north, south, east, west and centre of the cafeteria with ten questionnaires of each sample menu, randomly distributing menu versions 1, 2, 3 and 4 to willing participants in their designated area.

First, participants were exposed to the sample menu and told to respond to a question on purchase intent to select each menu item. Second, participants were asked to respond to three questions regarding their self-reported subjective nutrition knowledge. Lastly, respondents' demographic information (e.g. gender, age, ethnicity, etc.) was asked. Prior to the actual data collection, a pilot study was administered to ten graduate students to determine whether the respondents clearly understood the measurement items and to ensure measurement face validity.

\section{Measures}

\section{Independent measures}

There were three independent variables in the study: (i) calorie information (presence $v$. absence: CI); (ii) recommended daily calorie intake information (presence $v$. absence: RDCI); and (iii) respondents' subjective nutrition knowledge (SNK). The operationalization of CI and RDCI is illustrated in Fig. 2. In addition, SNK was measured with multiple statements based on a previous research study using an eleven-point Likert-type scale $(0=$ 'not at all'; $10=$ 'extremely') (43), but modified to fit the current study. The three SNK statements were: (i) 'In general, how much do you think you know about the topic of nutrition?'; (ii) 'I do not really know very much about nutrition in general'; and (iii) 'Compared to most people, I am quite knowledgeable about nutrition'.

\section{Dependent measure}

The dependent variable was respondents' intention to select lower-calorie foods using an eleven-point Likerttype scale. Participants responded to the statement: 'Based on the menu, please rate your purchase intention toward each menu item' ( $0=$ 'very probably not'; $10=$ 'definitely'). In order to empirically operationalize the construct, the following formula was used:

$$
\begin{aligned}
& \text { Intention to select lower-calorie food } \\
& =\frac{\text { Sum of ratings of the three lowest-calorie items }}{\text { Sum of ratings of all six items }} \times 100 \text {. }
\end{aligned}
$$

The three lowest-calorie sandwiches in the numerator included the Veggie Burger, Tendergrill Chicken Sandwich and Deluxe Cheeseburger. Therefore, the intention to select the lower-calorie food ranged from 0 to 100; 0 meant that respondents selected the higher-calorie menu items and 100 meant that the lower-calorie foods were chosen.

\section{Data analysis}

Prior to model testing, data were tested for univariate and multivariate outliers and normality using the statistical software package IBM SPSS Statistics Version 22.0. There were no univariate outliers detected and no violation of normality. However, eight multivariate outliers were identified using Mahalanobis' distance and were deleted for model testing. As a result, a sample of 192 was used for model testing. Assumptions of a multiple regression (i.e. normality, linearity and homoscedasticity) were checked using scatter plots and a normal Q-Q plot. The results revealed that those assumptions were satisfied enough to run a multiple regression.

\section{Results}

\section{Description of sample}

A total sample population of 192 students composed the study. Table 1 presents the demographic profile of the 

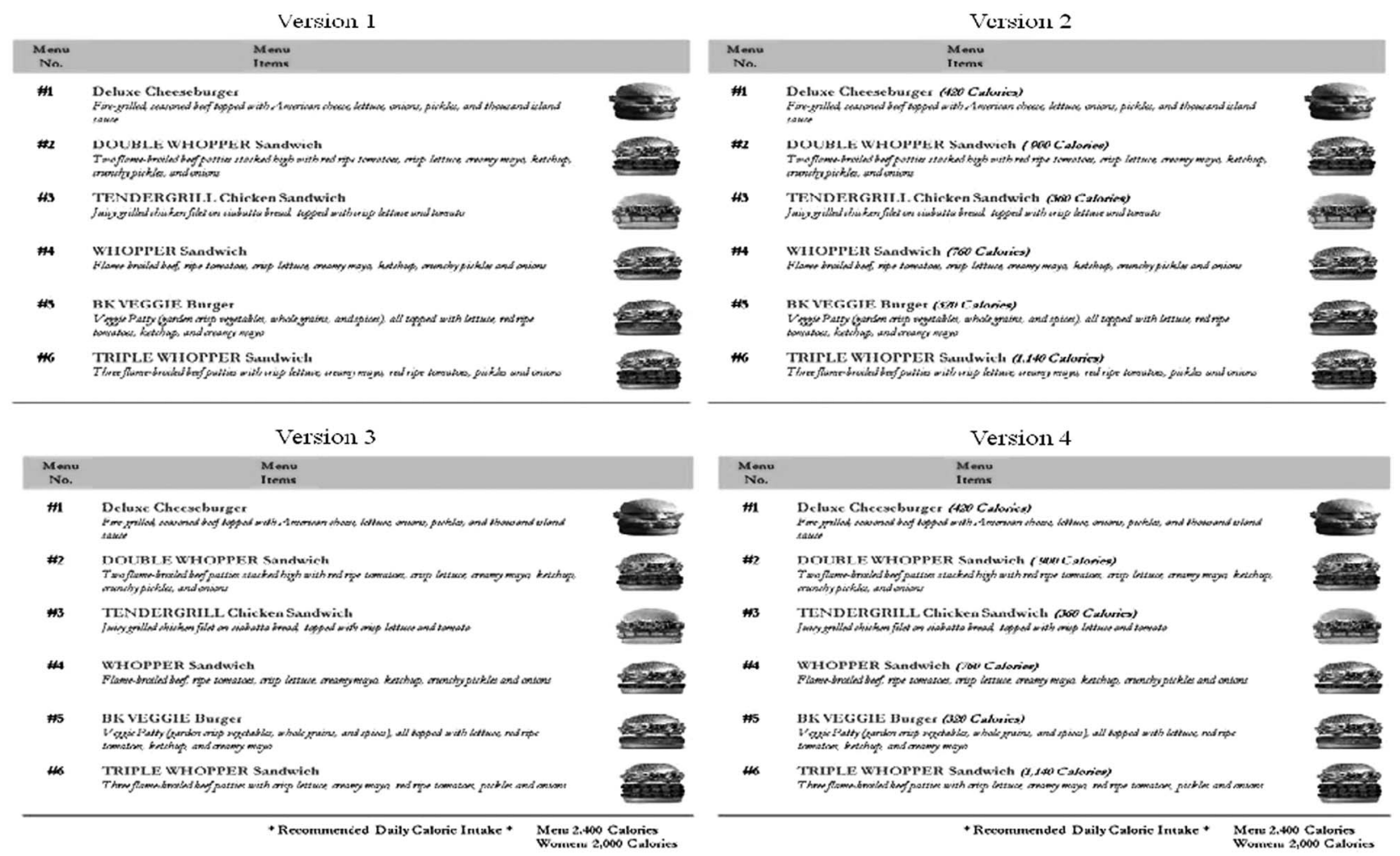

Fig. 2 Four versions of stimulus materials (note: version 1-4 sample menus were colour printed on an 8 in $\times 11$ in $(20.3 \mathrm{~cm}$ $\times 27.9 \mathrm{~cm}$ ) sheet exactly as presented here)

Table 1 Demographic profile of the sample of college students ( $n$ 192) from a large, public university in the Southwest USA

\begin{tabular}{|c|c|c|c|}
\hline Characteristic & Category & $n$ & $\%$ \\
\hline \multirow[t]{2}{*}{ Gender } & Male & 77 & $40 \cdot 1$ \\
\hline & Female & 115 & 59.9 \\
\hline \multirow[t]{3}{*}{ Age } & Under 18 years & 27 & $14 \cdot 1$ \\
\hline & 19-23 years & 132 & 68.8 \\
\hline & 24 years or above & 33 & $17 \cdot 1$ \\
\hline \multirow{5}{*}{$\begin{array}{l}\text { University } \\
\text { classification }\end{array}$} & Freshman & 40 & 20.9 \\
\hline & Sophomore & 31 & $16 \cdot 2$ \\
\hline & Junior & 31 & $16 \cdot 2$ \\
\hline & Senior & 76 & 39.8 \\
\hline & Graduate & 13 & 6.8 \\
\hline \multirow[t]{5}{*}{ Ethnicity } & White & 122 & 63.5 \\
\hline & Hispanic & 38 & $19 \cdot 8$ \\
\hline & African-American & 8 & 4.2 \\
\hline & Asian & 21 & 10.9 \\
\hline & Other & 3 & 1.5 \\
\hline \multirow{6}{*}{$\begin{array}{l}\text { Frequency of dining } \\
\text { away from home } \\
\text { (per week) }\end{array}$} & Less than once & 9 & 4.7 \\
\hline & Once & 28 & 14.6 \\
\hline & $2-3$ times & 76 & $39 \cdot 6$ \\
\hline & $4-5$ times & 48 & $25 \cdot 0$ \\
\hline & $6-7$ times & 12 & $6 \cdot 3$ \\
\hline & More than 7 times & 19 & 9.9 \\
\hline \multirow[t]{4}{*}{ BMI } & Underweight $\left(<18.5 \mathrm{~kg} / \mathrm{m}^{2}\right)$ & 11 & 5.9 \\
\hline & Normal $\left(18.5-24.9 \mathrm{~kg} / \mathrm{m}^{2}\right)$ & 118 & 62.8 \\
\hline & Overweight $\left(25.0-29.9 \mathrm{~kg} / \mathrm{m}^{2}\right)$ & 46 & 24.5 \\
\hline & Obese $\left(\geq 30.0 \mathrm{~kg} / \mathrm{m}^{2}\right)$ & 13 & 6.9 \\
\hline
\end{tabular}

study sample, showing that $40 \cdot 1 \%$ of the respondents were male and $59.9 \%$ were female. The average age of the participants was 21.8 (SD 3.6) years and about $93 \%$ of the respondents were undergraduate students. The majority of respondents were White $(63.5 \%)$, followed by Hispanic (19.8\%), Asian (10.9\%) and African-American (4.2\%). About $40 \%$ of the respondents reported that they dined out two or three times per week (39.6\%); $25.0 \%$ of the respondents dined out four or five times per week; and $14.6 \%$ responded that they ate out only once per week. The majority of the respondents had a BMI within the healthy range $(62.8 \%)$, followed by overweight $(24.5 \%)$, obese (6.9\%) and underweight (5.9\%).

\section{Preliminary analysis}

Before testing the hypotheses, a simple ANOVA was conducted in order to look at whether there was a difference in intention to select lower-calorie menu items among the four study groups. The test indicated that a significant difference existed among groups $(F(3,188)=3 \cdot 67$, $P<0.05)$. This finding suggested that further hypothesis testing was needed in order to precisely predict how nutrition information (calorie and recommended daily calorie intake information) affects respondents' purchase intention.

\section{Hypotheses tests of purchase intent}

The hypotheses were tested using a multiple regression analysis with 'intention to select lower-calorie menu items' as the dependent variable and 'CI', 'RDCI' and 'SNK' as the independent variables, controlling for gender, age, dining 
out frequency and BMI. The results of the multiple regression analysis are presented in Table 2.

Table 2 shows the testing of Hypotheses 1-3. Hypothesis 1 predicted that the calorie information on the menu board would have a significant impact on intention to select lower-calorie menu items. Hypothesis 1 was supported; respondents who were given calorie information had a significantly higher intention to select lower-calorie foods than those who were not provided calorie information $(\beta=0.24, P<0 \cdot 001)$. Placing the recommended daily calorie intake information on a menu board did not influence respondents' intention to select lower-calorie menu items $(\beta=0 \cdot 11, P=0 \cdot 081)$; therefore, Hypothesis 2 was not supported. The regression analysis results supported Hypothesis 3; the level of subjective nutrition

Table 2 Summary of multiple regression analysis for variables predicting purchase intention among college students $(n$ 192) from a large, public university in the Southwest USA

\begin{tabular}{|c|c|c|c|c|}
\hline Variables & $B$ & SE $(B)$ & $\beta$ & $t$ \\
\hline Constant & 36.31 & $13 \cdot 30$ & - & $2 \cdot 73^{\star \star}$ \\
\hline $\mathrm{Cl}^{*}$ & $9 \cdot 30$ & 2.40 & 0.24 & $3 \cdot 88^{\star \star *}$ \\
\hline $\mathrm{RDCl} \dagger$ & 4.22 & 2.41 & 0.11 & 1.76 \\
\hline SNK‡,§ & 3.67 & 0.72 & 0.33 & $5 \cdot 09^{\star \star \star}$ \\
\hline \multicolumn{5}{|c|}{ Potential confounding variables } \\
\hline Gender & 14.77 & 2.49 & 0.37 & $5.93^{\star \star \star}$ \\
\hline Age & -0.58 & 0.34 & -0.11 & -1.71 \\
\hline Frequency of dining out & -1.08 & 1.01 & -0.07 & -1.07 \\
\hline BMI $\|$ & 0.25 & 0.31 & 0.051 & -0.81 \\
\hline$R^{2}$ & \multicolumn{4}{|c|}{0.34} \\
\hline Adj. $R^{2}$ & \multicolumn{4}{|c|}{0.31} \\
\hline$F$ value & \multicolumn{4}{|c|}{$12 \cdot 99^{\star \star \star}$} \\
\hline
\end{tabular}

${ }^{\star \star} P<0.01,{ }^{\star \star \star} P<0.001$.

${ }^{*}$ Calorie information.

†Recommended daily calorie intake information.

¥Subjective nutrition knowledge.

§Subjective nutrition knowledge: mean 6.46 (SD 1.76); range 0-10.

||BMI: underweight $\left(<18.5 \mathrm{~kg} / \mathrm{m}^{2}\right)$, healthy weight $\left(18.5-24.9 \mathrm{~kg} / \mathrm{m}^{2}\right)$, overweight $\left(25 \cdot 0-29.9 \mathrm{~kg} / \mathrm{m}^{2}\right)$, obese $\left(\geq 30.0 \mathrm{~kg} / \mathrm{m}^{2}\right)$. knowledge had a significant impact on respondents' intention to select lower-calorie menu items $(\beta=0 \cdot 33$, $P<0.001)$.

In order to test the true effects of calorie information on the respondents' purchase intention, the analysis included potential confounding variables (i.e. gender, age, dining out frequency and BMI) in the model. The results found a significant impact of gender on purchase intention $(\beta=0.37, P<0 \cdot 001)$; however, there were no significant impacts of age, frequency of dining out and BMI. Therefore, further analysis was conducted to see how gender affected the respondents' purchase intention by examining male and female gender groups and a combined group (Group 1: no CI or RDCI; Group 2: only CI; Group 3: only RDCI; Group 4: both CI and RDCI). Figure 3 depicts that female respondents showed significantly higher intention to select lower-calorie menu items than male respondents. Then a series of $t$ tests comparing males and females for each condition was conducted and found that a significantly higher intention to select lower-calorie foods existed in female groups (Group 1: $t=-0.86, P=0.396$; Group 2: $t=-2 \cdot 13, P<0 \cdot 05$; Group 3: $t=-2 \cdot 71, P<0 \cdot 01$; Group 4: $t=-6 \cdot 26, P<0 \cdot 001)$. As indicated in Fig. 3 and test results, the differences between male and female groups were significant only when calorie information or recommended daily calorie intake information or both were presented on the menu board.

\section{Discussion}

The current study was undertaken to explore the impact of information about calorie content and recommended daily calorie intake displayed on a sample restaurant menu in college students. Additionally, the research examined the effect of subjective nutrition knowledge on intention to

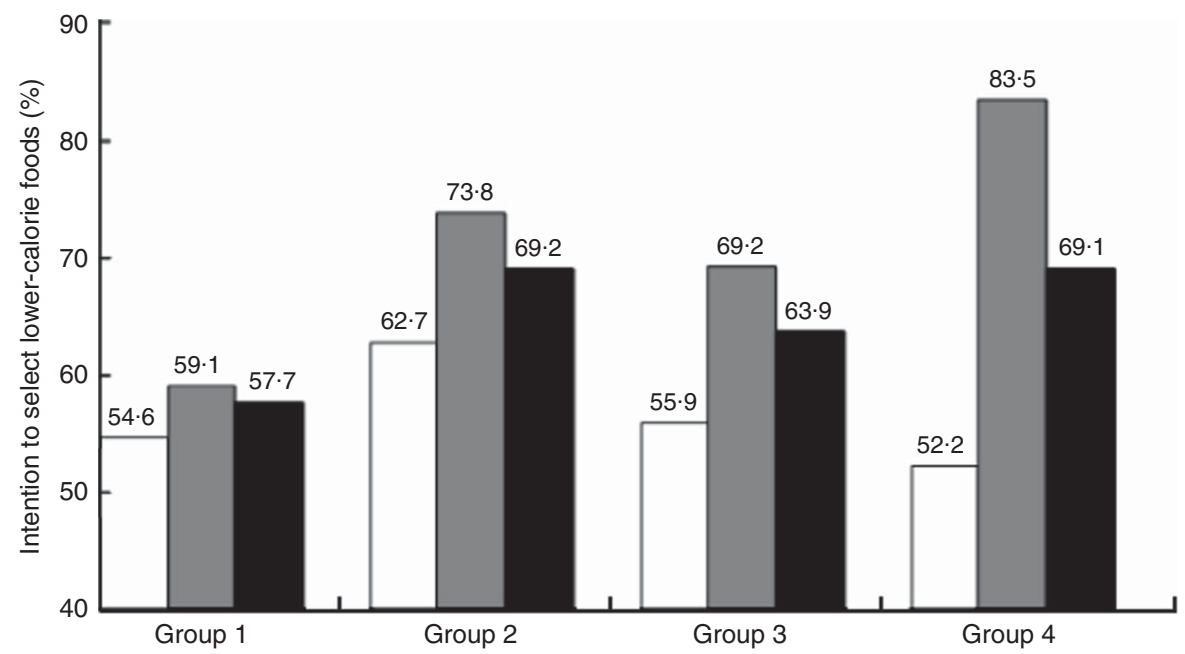

Fig. 3 Ratings of intention to select lower-calorie menu items, by gender ( $\square$, male; $\square$, female) and overall ( $\square$ ), according to experimental group (Group 1, no Cl or RDCl; Group 2, only Cl; Group 3, only RDCl; Group 4, both $\mathrm{Cl}$ and RDCl), among college students ( $n$ 192) from a large, public university in the Southwest USA ( $\mathrm{Cl}$, calorie information; RDCl, recommended daily calorie intake information) 
select lower-calorie foods. Researchers from Carnegie Mellon reported recently that no matter how much calorie information is on the menu, people still choose the food they like, rather than what is healthier ${ }^{(43)}$. However, since increase in body weight and BMI is significant, although modest, during 4 years of college ${ }^{(44)}$, understanding the health behaviours of Generation $\mathrm{Y}$ college students is important.

The results of the present study indicate that calorie content information on the menu and respondents' subjective nutrition knowledge had a significant impact on Generation Y's intention to select lower-calorie foods, with a much greater effect on females than males. A previous focus group study found that college students wanted nutritional labels when making purchase decisions, desiring labels to be readily available and easy to locate ${ }^{(45)}$. Similar to the present study, the presence of caloric information on restaurant menus significantly affected purchase intent of college students ${ }^{(46)}$. So are Generation $\mathrm{Y}$ unique in wanting nutrition labelling on menus more than other generational groups? Perhaps yes, since 'health is always top-of-mind among Millennials' and 'they often feel conflicted about eating out for this reason; ... looking for healthier options and checking out nutrition information on menus ${ }^{(47)}$. Generation $\mathrm{Y}$ have concerns about the time spent seeking information, especially if it takes them away from things they consider more important ${ }^{(48)}$, while nutrition facts on restaurant menus can be quickly obtained.

On the other hand, unlike calorie information, recommended daily calorie intake information had a relatively weak impact on menu decisions. This could just be due to menu formatting. According to the guidelines of the Food and Drug Administration, recommended daily calorie intake information is provided at the bottom right corner of the menu board, while calorie information is located next to the menu item ${ }^{(4)}$. That means calorie information is more prominent than recommended daily calorie intake information. According to eye-tracking research on nutrition label use, label location is one of the most important factors that increases consumers' attention, especially time viewing nutrition labels ${ }^{(49)}$.

The findings of the current study also showed that subjective nutrition knowledge had a positive effect on respondents' purchase intention to select lower-calorie foods. Some previous research studies have indicated that nutrition information positively influences US customers' nutrition-related attitudes, such as positive attitudes towards healthy menu items and lower-calorie foods ${ }^{(30,50)}$. College students who have high subjective nutrition knowledge and normal BMI conduct significantly more critical evaluations of fast-food menu labels than do their counterparts $^{(51)}$. Furthermore, according to previous studies, consumers' subjective knowledge has significant impact on decision making and behaviour ${ }^{(52,53)}$. From this perspective, consumers' subjective nutrition knowledge could be considered as their 'confidence level' about their nutrition knowledge. If people are confident about nutrition knowledge, they tend to care about what they eat. The posting of calorie information on menu boards may not resolve the obesity epidemic, but it could have a significant, gradual effect over time on continual healthier eating decisions of Generation $\mathrm{Y}$ consumers if the consequences result in positive personal outcomes, such as healthy weight. Even if only some people make slightly better, healthier choices, there appears to be benefit in providing calorie information.

The present study also found that gender plays a significant and important role in purchase intent for lowercalorie menu items. Female respondents were significantly more affected by the calorie information provided on the menu than male respondents. This is consistent with previous findings ${ }^{(54)}$, possibly due to females being more likely to read food labels than males ${ }^{(55-57)}$. However, one study found no gender differences in recall of point-ofselection nutrition information or in self-reported effects of point-of-selection nutrition information on overall food choices by college students ${ }^{(58)}$.

Despite its implications, the current study is not free from limitations. The data were collected only at one university in the Southwest USA using a convenience sample with only fifty respondents in each menu group. Therefore, generalizing the findings to other parts of the USA or other countries is limited. Another limitation is that no price information appeared on the manipulated menus. This might distort respondents' purchase intention when selecting a menu item, but, on the other hand, could have discouraged price from influencing respondents' menu decision. The sample menus utilized just main dishes (i.e. sandwiches) and excluded side dishes and drinks. This might undermine the real effect by excluding extra calories acquired through side dishes and drinks. Since the current study evaluated hypothetical choices, participants' orders may not perfectly reflect the calories that they would eat in an actual restaurant. Furthermore, the respondents under the controlled experiments could have the tendency to answer the questions in a manner viewed favourably by others (i.e. social desirability bias).

\section{Conclusion}

The current study found that nutrition information on the menu board had a positive impact on Generation Y consumers' decisions in choosing lower-calorie menu options. This finding would suggest that the new menu labelling law required of chain restaurants will be beneficial at encouraging lower-calorie menu selections in younger populations, while this is contrary to a study of all age groups eating at fast-food restaurants prior to and soon after New York City implemented nutrition labelling legislation in $2008^{(59)}$. When it comes to human choice, it 
would be hard to expect that nutrition labelling would work for everyone. Possibly restaurant menu labelling will over time be like grocery product nutrition labels, where greater consumer usage has been associated with health beliefs, diet-specific self-efficacy and placing a higher priority on health and nutrition ${ }^{(60)}$. College students' belief in nutrition information on grocery food labels was the only belief that distinguished users and non-users of labels in grocery products ${ }^{(61)}$. For those who seek this type of nutrition information at a restaurant, it appears beneficial for consumers to make an informed decision on the selection of lower-calorie food options when calorie information is displayed ${ }^{(62)}$.

Another positive side of menu labelling is that restaurants tend to work harder to provide lower-calorie options when they are required to display calorie information. If food-service operators support healthier food trends by providing nutrition/calorie information on their menus, this could lead to improved customer relations and business growth ${ }^{(63)}$. From the present study's findings that subjective nutrition knowledge can be utilized as a factor in influencing consumers' eating behaviour, nutrition information and promotional campaigns that increase consumers' subjective nutrition knowledge and selfefficacy could focus on promoting healthy products and healthy eating behaviours. Moreover, food-service operators should be encouraged to inform people about the beneficial aspects of healthy eating (i.e. lower-calorie diet) by incorporating general nutrition information in their nutrition materials and menu labels.

\section{Acknowledgements}

Financial support: This research received no specific grant from any funding agency in the public, commercial or notfor-profit sectors. Conflicts of interest: None. Authorship: M.G.R.: primary writer. H.-W.J.: writer. H.-W.J., E.-K.C. and H.-S.K.: participated in collecting research and analysed data. Ethics of buman subject participation: The study protocol was approved by Texas Tech University's Internal Review Board.

\section{References}

1. Lin B (2013) Food-away-from-home. http://www.ers. usda.gov/topics/food-choices-health/food-consumptiondemand/food-away-from-home.aspx\#.U5CodvmwJCg (accessed December 2015)

2. Nielsen (2015) We are what we eat: healthy eating trends around the world. Nielsen Global Health and Wellness Report. http://www.nielsen.com/content/dam/nielsenglobal/ eu/nielseninsights/pdfs/Nielsen\%20Global\%20Health\%20and \%20Wellness\%20Report\%20-\%20January\%202015.pdf (accessed February 2016).

3. Failla J (2015) Consumer insights on healthy eating. Prepared Foods 184, 60-66.

4. Federal Register (2014) Nutrition labeling of standard menu items in restaurants and similar retail food establishments. https://www.federalregister.gov/articles/2014/12/01/201427833/food-labeling-nutrition-labeling-of-standard-menu-itemsin-restaurants-and-similar-retail-food/ (accessed February 2016).

5. National Restaurant Association (2016) Menu Labeling. http:// www.restaurant.org/Menu-Labeling (accessed October 2016).

6. King County Public Health (2010) Amended King County Nutrition Labeling Regulation. http://www.kingcounty. gov/healthservices/health/nutrition/\%7e/media/health/ publichealth/documents/healthyeating/StakeholdersMemoJune 2010.ashx (accessed February 2016).

7. New York City Board of Health (2006) Notice of adoption of an amendment (\$81.50) to article 81 of the New York City health code. http://www.nyc.gov/html/doh/downloads/pdf/ public/notice-adoption-hc-art81-50.pdf (accessed February 2016).

8. Baertlein L (2012) US McDonald's to put calorie counts in lights. http://www.reuters.com/article/2012/09/12/usmcdonalds-calories-idUSBRE88B0YL20120912 (accessed February 2016).

9. Panera Bread (2010) Panera Bread first national restaurant concept to post calorie information on all menu boards. http://www.bakeryonline.com/doc/panera-bread-firstnational-restaurant-0001 (accessed February 2016).

10. DeVaney SA (2015) Understanding the millennial generation. J Financ Serv Professionals 69, 11-14.

11. Madsen L \& Cameron H (2007) Demystifying millennial students: Fact or fiction. http://cedar.wwu.edu/cgi/viewcontent. cgi?article $=1024 \&$ content=library_facpubs (accessed October 2016).

12. Cohen M. (2016) Segment and sell to Gen Y: 10 ways younger and older millennials shop differently. https://www. npd.com/wps/portal/npd/us/news/tips-trends-takeaways/10ways-younger-and-older-millennials-shop-differently/ (accessed October 2016).

13. National Center for Education Statistics (2015) Table 105.20: Enrollment in elementary, secondary, and degree-granting postsecondary institutions, by level and control of institution, enrollment level, and attendance status and sex of student: Selected years, fall 1990 through fall 2024. http:// nces.ed.gov/programs/digest/d14/tables/dt14_105.20.asp? current=yes (accessed January 2016).

14. American College Health Association (2009) American College Health Association-National College Health Assessment Spring 2008 Reference Group Data Report (abridged). J Am Coll Health 57, 477-488.

15. Brownell KD, Schwartz MB, Puhl RM et al. (2009) The need for bold action to prevent adolescent obesity. J Adolesc Health 45, 3 Suppl., S8-S17.

16. Gerend MA (2009) Does calorie information promote lower calorie fast food choices among college students? J Adolesc Health 44, 84-86.

17. Lee K, Conklin M, Cranage DA et al. (2014) The role of perceived corporate social responsibility on providing healthful foods and nutrition information with healthconscious as a moderator. Int J Hospit Manage 37, 29-37.

18. Bleich SN, Wolfson JA \& Jarlenski MP (2015) Calorie changes in chain restaurant menu items. Am J Prev Med 48, 70-75.

19. Bleich SN, Wolfson JA \& Jarlenski MP (2016) Calorie changes in large chain restaurants. Am J Prev Med 50, e1-e8.

20. Grunert KG \& Wills JM (2007) A review of European research on consumer response to nutrition information on food labels. J Public Health 15, 385-389.

21. Elbel B, Gyamfi J \& Kersh R (2011) Child and adolescent fast-food choice and the influence of calorie labeling: a natural experiment. Int J Obes (Lond) 35, 493-500.

22. Finkelstein EA, Strombotne KL, Chan NL et al. (2011) Mandatory menu labeling in one fast-food chain in King County, Washington. Am J Prev Med 40, 122-127. 
23. Harnack L, French S, Oakes JM et al. (2008) Effects of calorie labeling and value size pricing on fast food meal choices: results from an experimental trial. Int J Behav Nutr Phys Act 5, 63.

24. Chu YH, Frongillo EA, Jones SJ et al. (2009) Improving patrons' meal selections through the use of point-of-selection nutrition labels. Am J Public Health 99, 2001-2005.

25. Bassett MT, Dumanovsky T, Huang C et al. (2008) Purchasing behavior and calorie information at fast-food chains in New York City, 2007. Am J Public Health 98, 1457-1459.

26. Roseman MG, Mauthe-Soulek K \& Higgins JA (2013) Relationships among grocery nutrition label users and consumers' attitudes and behavior toward restaurant menu labeling. Appetite 71, 274-278.

27. Nikolaou CK, Hankey CR \& Lean MEJ (2015) Calorielabelling: does it impact on calorie purchase in catering outlets and the views of young adults? Int J Obes (Lond) 39, 542-545.

28. Long MW, Tobias DK, Cradock AL et al. (2015) Systematic review and meta-analysis of the impact of restaurant menu calorie labeling. Am J Public Health 105, e11-e24.

29. Breck A, Cantor J, Martinez O et al. (2014) Who reports noticing and using calorie information posted on fast food menus? Appetite 81, 30-36.

30. Hwang J \& Lorenzen CL (2008) Effective nutrition labeling of restaurant menu and pricing of healthy menu. J Foodserv 19, $270-276$.

31. Sun YC (2008) Health concern, food choice motives, and attitudes toward healthy eating: the mediating role of food choice motives. Appetite 51, 42-49.

32. Jang YJ, Kim WG \& Bonn MA (2011) Generation Y consumers' selection attributes and behavioral intentions concerning green restaurants. Int J Hospit Manage 30, 803-811.

33. Fromm J (2014) Millennial foodies inspire innovative culinary trends. http://www.millennialmarketing.com/ 2014/03/millennial-foodies-inspire-innovative-culinary-trends/ (accessed December 2015).

34. Dugan A (2013) Fast food still major part of US diet. http:// www.gallup.com/poll/163868/fast-food-major-part-diet.aspx (accessed December 2015).

35. Barton C, Koslow L, Fromm J et al. (2012) Millennial passions: food, fashion, and friends. http://www.bcg.com/ documents/file121010.pdf (accessed May 2015).

36. Saleh N (2012) Four millennial eating habits that are changing the way we eat. http://www.policymic.com/articles/ 3724/four-millennial-eating-habits-that-are-changing-the-waywe-eat (accessed January 2016).

37. Yang CL, Khoo-Lattimore C \& Lai MY (2014) Eat to live or live to eat? Mapping food and eating perception of Malaysian Chinese. J Hospit Mark Manage 23, 579-600.

38. Alba JW \& Hutchinson JW (2000) Knowledge calibration: what consumers know and what they think they know. J Consum Res 27, 123-134.

39. Pieniak Z, Aertsens J \& Verbeke W (2010) Subjective and objective knowledge as determinants of organic vegetables consumption. Food Qual Prefer 21, 581-588.

40. Hess R, Visschers VHM \& Siegrist M (2012) The role of health-related, motivational and sociodemographic aspects in predicting food label use. A comprehensive study. Public Health Nutr 15, 407-414.

41. Kolodinsky J, Harvey-Berino JR, Berlin L et al. (2007) Knowledge of current dietary guidelines and food choice by college students: better eaters have higher knowledge of dietary guidance. J Am Diet Assoc 107, 1409-1413.

42. Coulson N S (2000) An application of the stages of change model to consumer use of food labels. Br Food J 102, 661-668.

43. Rea S (2013) Recommended calorie information on menus does not improve consumer choices, Carnegie Mellon study shows. http://www.cmu.edu/news/stories/archives/2013/ july/july18_menulabeling.html (accessed December 2015).

44. Racette SB, Deusinger SS, Strube MJ et al. (2008) Changes in weight and health behaviors from freshman through senior year of college. J Nutr Educ Behav 40, 39-42.

45. Kolodinsky J, Green J, Michahelles M et al. (2008) The use of nutritional labels by college students in a food-court setting. J Am Coll Health 57, 297-302.

46. Mayfield K, Tang L \& Bosselman R (2014) Nutrition labeling for restaurant menu items: college students' preferences for nutrition information and its influence on purchase intention. J Qual Assur Hospit Tourism 15, 310-325.

47. Miller \& Associates (2014) Millennial customers. In US Restaurant, Food \& Beverage Market Research Handbook 2014-2015. http://www.marketresearch.com/ Richard-K-Miller-Associates-v $723 /$ Restaurant-Food-BeverageResearch-Handbook-8099132/ (accessed December 2015).

48. Weiler A (2005) Information-seeking behavior in Generation Y students: motivation, critical thinking, and learning theory. I Acad Librarian 31, 46-53.

49. Graham D, Orquin J \& Visschers V (2012) Eye tracking and nutrition label use: a review of the literature and recommendations for label enhancement. Food Policy 37, 378-382.

50. Hwang J \& Lin T (2010) Effects of food neophobia, familiarity, and nutrition information on consumer acceptance of Asian menu items. J Hospit Mark Manage 19, 171-187.

51. Hwang J (2013) The effects of nutrient ad disclosures of fast food menu items on consumer selection behaviors regarding subjective nutrition knowledge and body mass index. Br Food J 115, 1281-1296.

52. Raju P, Lonial S \& Mangold W (1995) Differential effects of subjective knowledge, objective knowledge, and usage experience on decision making: an exploratory investigation. J Consum Psychol 4, 153-180.

53. Dodd T, Laverie D, Wilcox J \& Duhan D (2005) Differential effects of experience, subjective knowledge, and objective knowledge on sources of information used in consumer wine purchasing. J Hospit Tourism Res 29, 13-19.

54. Lee-Kwan, Pan L, Maynard LM et al. (2016) Factors associated with self-reported menu-labeling usage among US adults. J Acad Nutr Diet 116, 1127-1135.

55. Driskell JA, Schake MC \& Detter HA (2008) Using nutrition labeling as a potential tool for changing eating habits of university hall patrons. J Am Diet Assoc 201, 2071-2076.

56. Krukowski RA, Harvey-Berino J, Kolodinsky J et al. (2006) Consumers may not use or understand calorie labeling in restaurants. J Am Diet Assoc 106, 917-920.

57. Levi A, Chan K \& Pence D (2006) Real men do not read labels: the effects of masculinity and involvement on college students' food decisions. J Am Coll Health 55, 91-98.

58. Freedman M (2011) Point-of-selection nutrition information influences choice of portion size in an all-you-can-eat university dining hall. J Foodserv Bus Res 14, 86-98.

59. Downs JS, Wisdom J, Wansink B et al. (2013) Supplementing menu labeling with calorie recommendations to test for facilitation effects. Am J Public Health 103, 1604-1609.

60. Graham DJ, Heidrick C \& Hodgin K (2015) Nutrition label viewing during a food-selection task: front-of-package labels vs nutrition facts labels. J Acad Nutr Diet 115, $1636-1646$.

61. Smith SC, Taylor JG \& Stephen AM (2000) Use of food labels and beliefs about diet-disease relationships among university students. Public Health Nutr 3, 175-182.

62. Seenivasan S \& Thomas D (2016) Negative consequences of nutrition information disclosure on consumptive behavior in quick-casual restaurants. J Econ Psychol 55, 51-60.

63. Story M, Kaphingst KM, Robinson-O'Brien R et al. (2008) Creating healthy food and eating environments: policy and environmental approaches. Annu Rev Public Health 29, 253-272. 